\title{
Correction to: Proceedings of the RILEM International Symposium on Bituminous Materials
}

Hervé Di Benedetto, Hassan Baaj, Emmanuel Chailleux, Gabriele Tebaldi, Cédric Sauzéat, and Salvatore Mangiafico

\section{Correction to:}

H. Di Benedetto et al. (eds.), Proceedings of the RILEM International Symposium on Bituminous Materials, RILEM Bookseries 27, https://doi.org/10.1007/978-3-030-46455-4

In the original version of the book, the following belated corrections have been Incorporated in chapter 156 and chapter 226 as follows:

Chapter 156: The author first name and last name has been changed.

Chapter 226: The missing author L.D. Poulikakos has been included now.

The chapter and book have been updated with the changes.

The updated version of these chapters can be found at 